\title{
Aromatase Inhibitor as Treatment for Severely Advanced Bone Age in Congenital Adrenal Hyperplasia: A Case Report
}

\author{
Wesley J. Goedegebuure Anita C.S. Hokken-Koelega \\ Department of Paediatrics, Subdivision Endocrinology, Erasmus University Medical Centre, \\ Rotterdam, The Netherlands
}

\section{Established Facts}

- Advanced bone age is frequently found in patients with congenital adrenal hyperplasia, which limits the available time for growth and often leads to near adult height below the average of the normal population.

- Treatment with aromatase inhibitors decelerates epiphyseal fusion, which potentially prolongs the period of growth and consequently increases near adult height.

- Serum levels of androstenedione, 17-hydroxyprogesterone, and testosterone will increase during aromatase inhibitor treatment.

\section{Novel Insights}

- Aromatase inhibitor treatment can result in a marked deceleration of bone maturation in patients with congenital adrenal hyperplasia with severely advanced bone age.

- Predicted adult height can increase greatly by means of aromatase inhibitor treatment.

- Aromatase inhibitor treatment caused difficulties in management of corticosteroid treatment, as serum levels of androstenedione, 17-hydroxyprogesterone, and testosterone are increased. Standard dosage of corticosteroid treatment was sufficient in this case, during the aromatase inhibitor treatment.

\section{Keywords}

Aromatase inhibitor - Congenital adrenal hyperplasia .

Short stature

\begin{abstract}
Introduction: Treatment with aromatase inhibitors ( $\mathrm{Al})$ is a potential novel treatment in patients with congenital adrenal hyperplasia $(\mathrm{CAH})$ and advanced bone age $(\mathrm{BA})$, to increase near adult height (NAH). Not much is known about the efficacy of $\mathrm{Al}$ treatment in $\mathrm{CAH}$ and how $\mathrm{Al}$ treatment will
\end{abstract}

influence the management of corticosteroid treatment. Case Presentation: At the age of 6 years and 3 months, a boy with salt-losing $\mathrm{CAH}$ presented with a BA 7 years in advance. Treatment with an Al (exemestane) was initiated to decelerate bone maturation. We continued the standard dosage of corticosteroid treatment. Precocious puberty was treated with 4 years of gonadotropin-releasing hormone agonist, while Al treatment was continued until attainment of $\mathrm{NAH}$. His NAH $177.7 \mathrm{~cm}$ (-0.8 SDS) was considerably higher than his predicted adult height of $151.3 \mathrm{~cm}(-4.6$ SDS) at the start of Al treatment. The higher serum androgen levels during $\mathrm{Al}$

\begin{tabular}{|c|c|}
\hline KARGER & $\begin{array}{l}\text { (c) } 2019 \text { The Author(s) } \\
\text { Published by S. Karger AG, Basel }\end{array}$ \\
\hline $\begin{array}{l}\text { E-Mail karger@karger.com } \\
\text { www.karger.com/hrp }\end{array}$ & $\begin{array}{l}\text { This article is licensed under the Creative Commons Attribution- } \\
\text { NonCommercial-NoDerivatives } 4.0 \text { International License (CC BY- } \\
\text { NC-ND) (http://www.karger.com/Services/OpenAccessLicense). } \\
\text { Usage and distribution for commercial purposes as well as any dis- } \\
\text { tribution of modified material requires written permission. }\end{array}$ \\
\hline
\end{tabular}


treatment did not result in short adult stature. Discussion/ Conclusion: This report shows that Al treatment can adequately decelerate bone maturation, causing predicted adult height to increase significantly in patients of $\mathrm{CAH}$ with accelerated bone maturation. We suggest continuing the same corticosteroid dosage during Al treatment and accepting higher serum androgen levels.

(C) 2019 The Author(s)

Published by S. Karger AG, Basel

\section{Introduction}

Advanced bone age (BA) is frequently found in patients with congenital adrenal hyperplasia $(\mathrm{CAH})[1]$, which limits the available time for growth and often leads to near adult height (NAH) below the average of the normal population (between -1 and -2 SDS) [2]. Treatment with aromatase inhibitors (AI) is a potential novel approach for short children with advanced BA. By inhibiting the aromatase enzyme, the conversion of androgens to estradiol is reduced. Estradiol primarily regulates the fusion of the epiphysis by decreasing progenitor cells in the chondrocytes and promoting senescence of the epiphysis [3-5]. The decelerated epiphyseal fusion, due to low levels of estradiol during AI treatment, potentially prolongs the period of growth and consequently increases adult height [6-8]. However, not much is known about the efficacy of AI treatment in $\mathrm{CAH}$.

Corticosteroid treatment in $\mathrm{CAH}$ is monitored by measuring serum levels of androstenedione, 17-hydroxyprogesterone (17OHP), and testosterone [9]. These parameters will increase during AI treatment, but it is unknown how this will influence the management of corticosteroid treatment in $\mathrm{CAH}$.

We report the effects of AI treatment on bone maturation and height gain in a boy with 11-beta-hydroxylase (CYP11B1) deficiency with markedly advanced BA. Secondly, this case report provides insight into the serum androgen levels during AI treatment in a boy with $\mathrm{CAH}$.

\section{Case Presentation}

\section{Advanced $B A$}

A boy with salt-losing CAH was presented at the Erasmus University Medical Centre - Sophia Children's Hospital at 5.5 years of age, for management of his $\mathrm{CAH}$. He had been treated with hydrocortisone $\left(12 \mathrm{mg} / \mathrm{m}^{2} /\right.$ day $)$ and fludrocortisone. Height was 123.4 $\mathrm{cm}(+1.4$ SDS, according to Dutch growth references [10]) and his target height was $185.5 \mathrm{~cm}(+0.2 \mathrm{SDS})$, based on a paternal and maternal height of 182 and $167 \mathrm{~cm}$, respectively. His BA was 8 years (2.5 years in advance), while his serum androgen levels had always been within the normal range. Figure 1 shows the growth chart and BA progression.

\section{Start of AI Treatment}

At age 6 years and 3 months, height was $129 \mathrm{~cm}(+1.4$ SDS). Tanner stage was A1G3P1, with a testicular volume of $3 \mathrm{~mL}$ bilaterally. His BA had increased to 13 years (7 years in advance), while serum androgen levels had remained within normal range. Due to this severely advanced BA, the Bayley and Pinneau predicted adult height $(\mathrm{PAH})$ was considerably lower than his target height (151.3 cm [-4.6 SDS] vs. 185.5 [+0.2 SDS], respectively). For that reason, treatment was started with an AI, once daily $25 \mathrm{mg}$ Aromasin (exemestane), to decelerate bone maturation.

Median serum levels of androgens are depicted in Table 1. After the start of AI treatment, androstenedione and 17OHP were on average increased, as expected. As hydrocortisone treatment with $12 \mathrm{mg} / \mathrm{m}^{2} /$ day resulted in normal androgen levels in the 2 years before AI treatment, we continued the same dosage of hydrocortisone (in $\mathrm{mg} / \mathrm{m}^{2} /$ day).

\section{Start of Puberty}

After 2.5 years of AI treatment, at the age of 8 years and 9 months, height was $144 \mathrm{~cm}(+1.3$ SDS), while bone maturation had decelerated and his BA had remained 13 years. As a result, the PAH had greatly increased during the AI treatment, from -4.6 to -1.5 SDS (Fig. 2).

At this visit, Tanner stage was A1G3P4 and the testes had a volume of $6 \mathrm{~mL}$ bilaterally. Gonadotropin-releasing hormone agonist (GnRHa) treatment was started to postpone puberty, and the AI treatment was put on hold. After cessation of AI treatment, however, BA started to progress again. We therefore reinitiated the AI treatment, which led to a new deceleration of bone maturation.

After the stop of AI treatment, while on GnRHa treatment, androgen levels were again within the normal range for a prepubertal boy. After reinitiating AI treatment, serum levels of androstenedione and 17OHP were again above the normal range, with a similar hydrocortisone dosage.

\section{Cessation of GnRHa Treatment}

At age 12 years and 6 months, height was $161.5 \mathrm{~cm}$ (+1 SDS) and BA had remained 13.5 years of age, which consequently led to a PAH of $184.3 \mathrm{~cm}$, within target height range. GnRHa treatment was discontinued after a treatment period of almost 4 years, AI treatment was continued.

During the pubertal period with AI treatment, serum levels of androstenedione and 17OHP remained above the normal range for a pubertal boy, with appropriate hydrocortisone treatment for CAH.

\section{Cessation of AI Treatment}

At the age of 15 years and 9 months, he attained his NAH of $177.7 \mathrm{~cm}$ (-0.8 SDS), BA was similar to calendar age. The AI treatment was discontinued.

Following AI treatment, salivary androstenedione and 17OHP levels were also measured in morning saliva. Salivary androstenedione was $0.9-1.0 \mathrm{nmol} / \mathrm{L}$ (normal range: $0.2-1.0$ ) and $17 \mathrm{OHP}$ was 1.0-2.0 nmol/L (normal range: 0.2-8.9) [11]. 


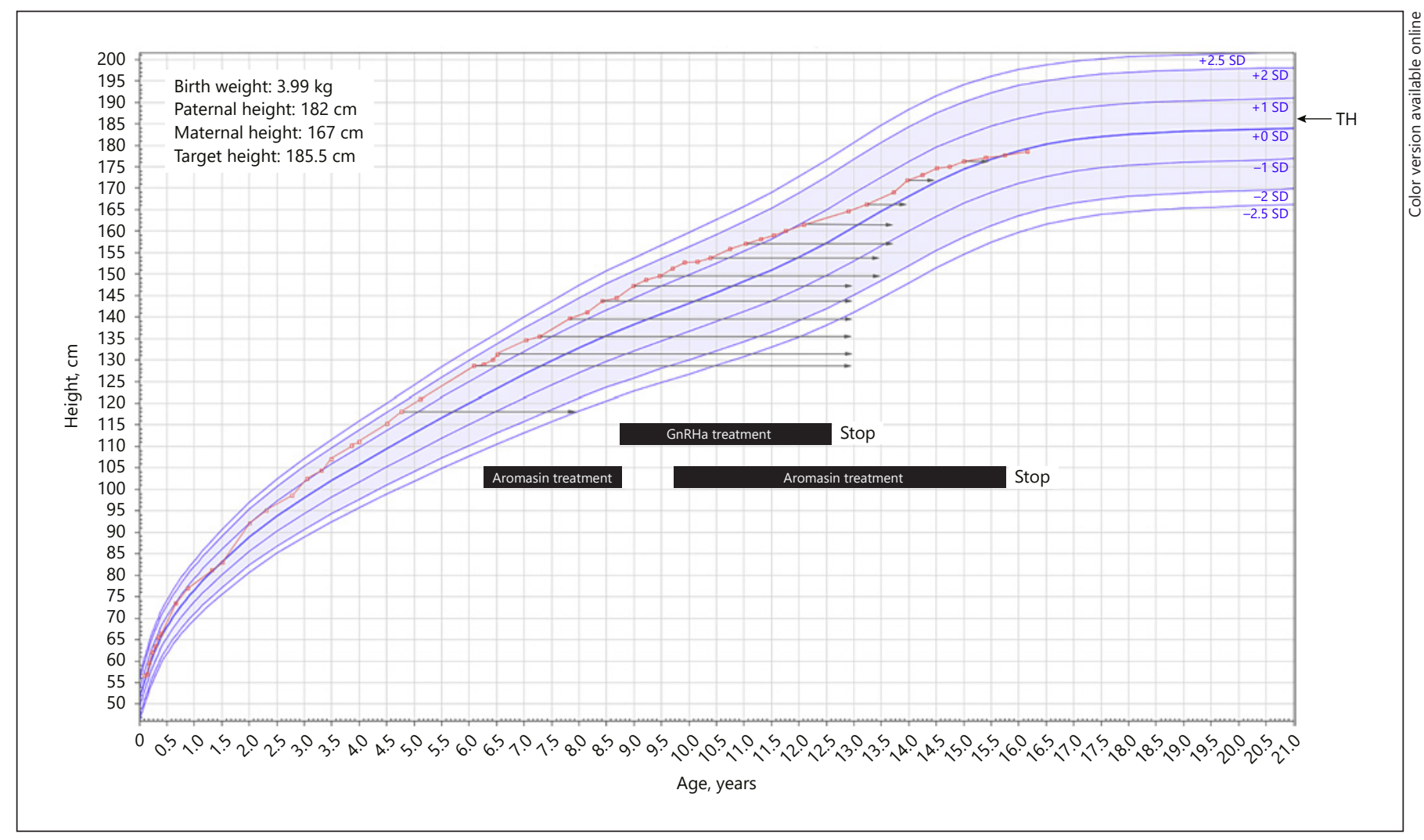

Fig. 1. Height for age compared to Dutch reference population [10]. Arrows point to BA at specific visits, black boxes indicate treatment regimen. GnRHa, gonadotropin-releasing hormone agonist; TH, target height.

Follow-Up after AI Treatment

Bone health index, the amount of cortical bone mass in the metacarpals, was measured frequently during AI treatment with Bone Expert (version 2.4.5.1) and also at cessation of AI treatment [12]. Bone health index continued to be 2 standard deviations above the reference population and did not decrease during AI treatment. Bone mineral density was also measured after 9 years of AI treatment using a dual-energy X-ray absorptiometry scan (Lunar Prodigy, GE Healthcare, UK), which was $1.150 \mathrm{~g} / \mathrm{cm}^{2}(-0.1$ SDS) for the total body.

\section{Discussion/Conclusion}

Advanced BA in children with $\mathrm{CAH}$ leads to a reduction of NAH. This patient illustrates AI treatment as a possible solution in case of advanced BA. AI treatment induced a marked deceleration of bone maturation, which led to a strong increase in NAH. However, it caused difficulties in the interpretation of the serum levels of androgen and thus management. Serum androgen levels were elevated throughout AI treatment with standard hydrocortisone dosage for $\mathrm{CAH}\left(12-13 \mathrm{mg} / \mathrm{m}^{2} /\right.$ day).

Aromatase Inhibitor for Advanced Bone Age in Congenital Adrenal Hyperplasia

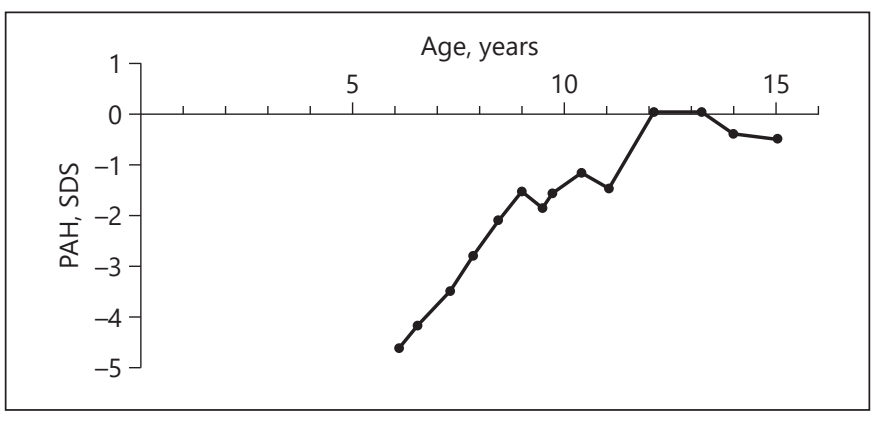

Fig. 2. Bayley and Pinneau prediction for adult height, plotted against age in years. PAH, predicted adult height; SDS, standard deviation score.

In this case, AI treatment for 9 years resulted in a marked increase in $\mathrm{NAH}$, which led to a NAH within the target height range and within the normal range of the population. Adult height prediction is difficult in case of an advanced BA by 7 years, but during AI treatment, the time for growth was significantly prolonged 
Table 1. Androgen levels before, during, and after aromatase inhibitor treatment

\begin{tabular}{|c|c|c|c|c|c|c|}
\hline & $\begin{array}{l}1 \\
\text { Before AI }\end{array}$ & $\begin{array}{l}2 \\
\text { Prepubertal AI }\end{array}$ & $\begin{array}{l}3 \\
\text { GnRHa only }\end{array}$ & $\stackrel{4}{\mathrm{AI}}+\mathrm{GnRHa}$ & $\begin{array}{l}5 \\
\text { Pubertal AI }\end{array}$ & $\begin{array}{l}6 \\
\text { After stop of AI }\end{array}$ \\
\hline Androstenedione, $\mathrm{nmol} / \mathrm{L}$ (normal range) & $2.2(0.4-2.6)$ & $27(0.7-3.8)$ & $2.8(1.0-3.8)$ & $12.3(1.0-5.2)$ & $25.4(2.0-10)$ & 0.9 (saliva) $(0.2-1.0)$ \\
\hline 17OHP, nmol/L (normal range) & $6.8(<10)$ & $13.5(<10)$ & $2.1(<10)$ & $17.1(<10)$ & $73.8(<10)$ & 1.5 (saliva) (1.0-8.9) \\
\hline Testosterone, nmol/L (normal range) & $0.6(<1.1)$ & $0.7(<1.1)$ & $0.3(<1.1)$ & $0.7(<1.1)$ & $11.7(0.1-29.5)$ & $14.1(10.0-30.0)$ \\
\hline
\end{tabular}

Mean levels per period are depicted, normal range for this period is stated in parentheses. 17OHP, 17-hydroxyprogesterone; AI, aromatase inhibitor; GnRHa, gonadotropin-releasing hormone agonist.

by a deceleration in bone maturation in the presence of normal height velocity. In boys with idiopathic short stature, slowing BA maturation using AI was found to be efficient and safe $[6,13]$. Two case reports of boys with $\mathrm{CAH}$ have shown adequate growth during growth hormone treatment with additional AI treatment [14, 15]. A study in Chinese boys and girls with $\mathrm{CAH}$ and central precocious puberty described normal NAH following combined AI and GnRHa treatment (without additional growth hormone treatment) to slow BA maturation during pubertal suppression [16]. They showed a significant increase in NAH during 2.4 years of AI combined with GnRHa treatment, compared with GnRHa only. One other study evaluated a lower dosage of corticosteroid treatment in combination with AI treatment and an androgen antagonist treatment in $\mathrm{CAH}$, showing normal growth and bone maturation, despite elevated adrenal steroid levels [17, 18]. That study suggests that a lower corticosteroid dosage might be sufficient during AI treatment in $\mathrm{CAH}$ patients. We present the first patient of $\mathrm{CAH}$ with markedly advanced $\mathrm{BA}$, which was treated for 9 years with AI until $\mathrm{NAH}$ attainment, combined with 4 years of GnRHa treatment because of early puberty, resulting in a significant increase in NAH.

Many children with $\mathrm{CAH}$ attain a short adult stature due to an early puberty and premature epiphyseal closure as a result of higher serum androgen levels in case of suboptimal treatment $[1,19-21]$. In our patient, BA was advanced, which points in the direction of androgen excess. However, both serum androstenedione and 17OHP levels were repeatedly within the normal range before the start of AI treatment.

During AI treatment, we experienced difficulties with the interpretation of the higher serum androgen levels, as they were increased due to AI treatment. Measurement of serum levels of androgens (androstenedione, $17 \mathrm{OHP}$, and testosterone) is essential in $\mathrm{CAH}$, but it is complicated by AI treatment as this increases all serum androgen levels [9]. In this case, we can assume that cor- ticosteroid treatment was well managed with a standard dosage for CAH of $12-13 \mathrm{mg} / \mathrm{m}^{2} /$ day. This was confirmed by the period without AI treatment and in the period after AI treatment, in which the serum and salivary androgen levels were within the normal range again. Our results also show that higher serum androgen levels during AI treatment do not result in short adult stature, probably as accelerated bone maturation is prevented by the low serum levels of estradiol. We suggest continuing the standard corticosteroid dosage for CAH during AI treatment and accepting higher serum androgen levels. However, when the serum androgen levels are extremely high and hydrocortisone undertreatment is suspected, we would suggest evaluating virilization, to measure serum ACTH in the early morning, and perform an ultrasound of the testes to evaluate if there is growth of adrenal rest tumors. Particularly in case of high hydrocortisone dosage, determining weight for length and measuring blood pressure is essential to test for symptoms of Cushing's syndrome.

Treatment with AI was well tolerated by our patient. We had chosen Aromasin, a steroidal AI, as it was the only available AI at that time. Nowadays, Letrozole and Anastrozole are most frequently used to reduce bone maturation in the treatment of short stature. These are nonsteroidal AIs and have a different inhibition on the aromatase enzyme compared with steroidal AIs such as Aromasin. Also, Letrozole is a more specific and potent AI compared to Anastrozole and Aromasin, which might also lead to higher serum androgen levels [22, 23]. However, effects of Letrozole and Anastrozole on serum androgen levels and efficacy in the treatment of $\mathrm{CAH}$ are unknown. Research should be performed in a larger study in patients with $\mathrm{CAH}$, to confirm our results.

We presented this $\mathrm{CAH}$ patient treated with $\mathrm{AI}$ as the treatment for short PAH. This patient shows that AI treatment can adequately decelerate bone maturation, causing $\mathrm{PAH}$ to increase significantly in patients of $\mathrm{CAH}$ with accelerated bone maturation. 


\section{Statement of Ethics}

We state that the subject and his parents have given their written informed consent to publish their case, in accordance with the Declaration of Helsinki.

\section{Disclosure Statement}

The authors have no conflicts of interest to declare.

\section{References}

1 Bonfig W. Growth and development in children with classic congenital adrenal hyperplasia. Curr Opin Endocrinol Diabetes Obes. $2017 \mathrm{Feb} ; 24(1): 39-42$.

2 Bretones P, Riche B, Pichot E, David M, Roy $\mathrm{P}$, Tardy V, et al.; French Collaborative CAH Growth Study Group. Growth curves for congenital adrenal hyperplasia from a national retrospective cohort. J Pediatr Endocrinol Metab. 2016 Dec;29(12):1379-88.

3 Smith EP, Boyd J, Frank GR, Takahashi H, Cohen RM, Specker B, et al. Estrogen resistance caused by a mutation in the estrogenreceptor gene in a man. N Engl J Med. 1994 Oct;331(16):1056-61.

4 Carani C, Qin K, Simoni M, Faustini-Fustini M, Serpente S, Boyd J, et al. Effect of testosterone and estradiol in a man with aromatase deficiency. N Engl J Med. 1997 Jul;337(2):91-5.

5 Nilsson O, Weise M, Landman EB, Meyers JL, Barnes KM, Baron J. Evidence that estrogen hastens epiphyseal fusion and cessation of longitudinal bone growth by irreversibly depleting the number of resting zone progenitor cells in female rabbits. Endocrinology. 2014 Aug;155(8):2892-9.

6 Hero M, Wickman S, Dunkel L. Treatment with the aromatase inhibitor letrozole during adolescence increases near-final height in boys with constitutional delay of puberty. Clin Endocrinol (Oxf). 2006 May;64(5):5103.

7 Carrascosa A, Audi L, Ferrandez MA, Ballabriga A. Biological effects of androgens and identification of specific dihydrotestosterone-binding sites in cultured human fetal epiphyseal chondrocytes. J Clin Endocrinol Metab. 1990 Jan;70(1):134-40.

8 Abu EO, Horner A, Kusec V, Triffitt JT, Compston JE. The localization of androgen receptors in human bone. J Clin Endocrinol Metab. 1997 Oct;82(10):3493-7.
9 Speiser PW, Arlt W, Auchus RJ, Baskin LS, Conway GS, Merke DP, et al. Congenital Adrenal Hyperplasia Due to Steroid 21-Hydroxylase Deficiency: An Endocrine Society Clinical Practice Guideline. J Clin Endocrinol Metab. 2018 Nov;103(11):4043-88.

10 Fredriks AM, van Buuren S, Burgmeijer RJ, Meulmeester JF, Beuker RJ, Brugman E, et al. Continuing positive secular growth change in The Netherlands 1955-1997. Pediatr Res. 2000 Mar;47(3):316-23.

11 de Groot MJ, Pijnenburg-Kleizen KJ, Thomas CM, Sweep FC, Stikkelbroeck NM, Otten BJ, et al. Salivary morning androstenedione and $17 \alpha-\mathrm{OH}$ progesterone levels in childhood and puberty in patients with classic congenital adrenal hyperplasia. Clin Chem Lab Med. 2015 Feb;53(3):461-8.

12 Thodberg HH, van Rijn RR, Tanaka T, Martin $\mathrm{DD}$, Kreiborg S. A paediatric bone index derived by automated radiogrammetry. Osteoporos Int. 2010 Aug;21(8):1391-400.

13 Mauras N, Gonzalez de Pijem L, Hsiang HY, Desrosiers P, Rapaport R, Schwartz ID, et al. Anastrozole increases predicted adult height of short adolescent males treated with growth hormone: a randomized, placebo-controlled, multicenter trial for one to three years. J Clin Endocrinol Metab. 2008 Mar;93(3):823-31.

14 Hawton K, Walton-Betancourth S, Rumsby G, Raine J, Dattani M. Growth Hormone With Aromatase Inhibitor May Improve Height in CYP11B1 Congenital Adrenal Hyperplasia. Pediatrics. 2017 Feb;139(2):e20160730.

15 Nour MA, Pacaud D. Height augmentation in $11 \beta$-hydroxylase deficiency congenital adrenal hyperplasia. Int J Pediatr Endocrinol. 2015;2015(1):12.

16 Juan L, Huamei M, Zhe S, Yanhong L, Hongshan C, Qiuli C, et al. Near-final height in 82 Chinese patients with congenital adrenal hyperplasia due to classic 21-hydroxylase deficiency: a single-center study from China. J Pediatr Endocrinol Metab. 2016 Jul;29(7):841-8.
17 Merke DP, Keil MF, Jones JV, Fields J, Hill S, Cutler GB Jr. Flutamide, testolactone, and reduced hydrocortisone dose maintain normal growth velocity and bone maturation despite elevated androgen levels in children with congenital adrenal hyperplasia. J Clin Endocrinol Metab. 2000 Mar;85(3):1114-20.

18 Laue L, Merke DP, Jones JV, Barnes KM, Hill S, Cutler GB Jr. A preliminary study of flutamide, testolactone, and reduced hydrocortisone dose in the treatment of congenital adrenal hyperplasia. J Clin Endocrinol Metab. 1996 Oct;81(10):3535-9.

19 Bonfig W, Bechtold S, Schmidt H, Knorr D, Schwarz HP. Reduced final height outcome in congenital adrenal hyperplasia under prednisone treatment: deceleration of growth velocity during puberty. J Clin Endocrinol Metab. 2007 May;92(5):1635-9.

20 Eugster EA, Dimeglio LA, Wright JC, Freidenberg GR, Seshadri R, Pescovitz OH. Height outcome in congenital adrenal hyperplasia caused by 21-hydroxylase deficiency: a meta-analysis. J Pediatr. 2001 Jan;138(1):2632.

21 Van der Kamp HJ, Otten BJ, Buitenweg N, De Muinck Keizer-Schrama SM, Oostdijk W, Jansen $M$, et al. Longitudinal analysis of growth and puberty in 21-hydroxylase deficiency patients. Arch Dis Child. 2002 Aug; 87(2):139-44.

22 Miller WR, Bartlett J, Brodie AM, Brueggemeier RW, di Salle E, Lønning PE, et al. Aromatase inhibitors: are there differences between steroidal and nonsteroidal aromatase inhibitors and do they matter? Oncologist. 2008 Aug;13(8):829-37

23 Neely EK, Kumar RB, Payne SL, Ranadive SA, Suchet DI. Letrozole vs anastrozole for height augmentation in short pubertal males: first year data. J Clin Endocrinol Metab. 2014 Nov; 99(11):4086-93. 